\title{
Hygienic Sanitary Items Usage and Ovulatory Cycle Knowledge in India
}

Karan Babbar ( $\sim$ phd17karanb@iima.ac.in )

Indian Institute of Management Ahmedabad https://orcid.org/0000-0001-6638-6573

Deepika Saluja

Others

Research

Keywords: Menstrual Hygiene Management, Sanitary items Usage, Ovulatory Cycles, NFHS-4, India

Posted Date: August 24th, 2020

DOI: https://doi.org/10.21203/rs.3.rs-33957/v2

License: (9) This work is licensed under a Creative Commons Attribution 4.0 International License. Read Full License 
The authors have withdrawn this preprint from Research Square 